\title{
Taeniosis-cysticercosis in man and animals in the Sierra of Northern Ecuador
}

\author{
R. Rodríguez-Hidalgo ${ }^{a}$, W. Benítez-Ortiz ${ }^{a}$, P. Dorny ${ }^{b}$, S. Geerts ${ }^{b}$, \\ D. Geysen ${ }^{\mathrm{b}}$, J. Ron-Román ${ }^{\mathrm{a}}$, F. Proaño-Pérez ${ }^{\mathrm{a}}$, \\ M.A. Chávez-Larrea ${ }^{\mathrm{a}}$, M. Barrionuevo-Samaniego ${ }^{\mathrm{a}}$, \\ M. Celi-Erazo ${ }^{\mathrm{a}}$, L. Vizcaíno-Ordóñez ${ }^{\mathrm{a}}, \mathrm{J}$. Brandt ${ }^{\mathrm{b}, *}$ \\ a Centro Internacional de Zoonosis, Universidad Central del Ecuador (UC), \\ PO Box 17-03-100, Quito, Ecuador \\ ${ }^{\mathrm{b}}$ Department of Animal Health, Prince Leopold Institute of Tropical Medicine, \\ Nationalestraat 155, B-2000 Antwerp, Belgium
}

Received 12 June 2003; received in revised form 2 September 2003; accepted 16 September 2003

\begin{abstract}
Taenia solium is endemic in the Andean region of Ecuador. The recent rediscovery of Taenia saginata in humans urges to reconsider some assumptions in relation to the epidemiology of the taeniosis/cysticercosis complex in this country.

Therefore, data were compiled on the infection of both tapeworms in man and animals in Pichincha and Imbabura provinces in the Andean region, north of Quito. On post mortem inspection 3 out of $806(0.37 \%)$ carcasses had T. saginata metacestodes, however, 35 sera out of $869(4.03 \%)$ showed circulating antigen in a monoclonal antibody-based sandwich ELISA (Ag-ELISA). Porcine cysticercosis was detected in 15 out of $2896(0.52 \%)$ carcasses and 93 out of 1032 serum samples (9.01\%) were positive in Ag-ELISA. In humans, 4.99\% (215 out of 4306) cases of antigen positives were found, whereas coprological examination of 1935 stools resulted in 30 positive cases (1.55\%). The limited number of adult tapeworms (29) that were collected does not allow firm conclusions on the proportion of each species, but in total 21 specimen were identified as $T$. saginata and 8 as T. solium. These data have been discussed in view of the epidemiology of human cysticercosis.

(C) 2003 Elsevier B.V. All rights reserved.
\end{abstract}

Keywords: Taenia saginata; Taenia solium; Prevalence; Zoonosis; Ecuador

\footnotetext{
* Corresponding author. Tel.: +32-3-247-6261; fax: +32-3-247-6264.

E-mail address: jbrandt@itg.be (J. Brandt).
} 


\section{Introduction}

Taenia saginata is one of the tapeworms of the small intestine of man, its metacestode, is specific for cattle. Distribution is almost cosmopolitan but where Taenia solium is equally present, the importance of $T$. saginata is often overshadowed by the latter, being of greater medical importance.

Reports on the prevalence of adult Taenia in Ecuador are given by López (1969) i.e. $0.66 \%$ without indication of the species but later interpreted as T. saginata (Pawlowski and Schultz, 1972). The prevalence of adult $T$. solium in this country was reported by Jiménez (1976) and Cruz et al. (1989) as being, respectively, 1.02 and $1.6 \%$.

T. solium cysticercosis has been reported both in humans i.e. $14.4 \%$ in the northern Sierra (Cruz, 1996) and in pigs in the southern Sierra of Ecuador i.e. 5.9\% by Jiménez (1976) and $12 \%$ by Benítez (1995).

There are no published reports on the presence of $T$. saginata metacestodes in Ecuador, the only documented evidence can be found in final year dissertations and is limited to slaughterhouse observations in the coastal region of the country. As such, infection levels, observed by post mortem inspection varied from 1.89 to $0.04 \%$ (Briones, 1969; Aragundi, 1969; Intriago, 1976; Sosa, 1981; Aragundi, 1999). There is no evidence of studies on bovine cysticercosis in the Andean Sierra or in the Amazon region of the country.

The objective of the present study was to evaluate whether the presence of $T$. saginata should be taken into account in epidemiological studies of $T$. solium-cysticercosis. Therefore, a survey on cysticercosis in humans, pigs and in bovines and on intestinal Taenia in the same region of the northern Andes of Ecuador has been conducted.

\section{Materials and methods}

The observations were made in two provinces of the Andean Sierra: Pichincha province, with the capital Quito and the neighbouring province to the north, Imbabura province with Ibarra as the provincial capital.

\subsection{Bovines}

Surveys were organised in two slaughterhouses: in the "Camal Municipal de Rastro de Ibarra", Imbabura Province and in the "Camal Metropolitano de Quito" Pichincha Province. The slaughterhouse of Ibarra was visited 20 times between December 2000 and January 2001; a total of 374 carcasses were inspected and 397 blood samples collected from bovines of different age, sex and race. The limited number of animals slaughtered per day allowed for a close inspection of the so-called predilection sites: masseters, myocard, oesophagus and diaphragm, which are usually not subject to regular inspection in this slaughterhouse. When an animal was found positive, the complete carcass and all the organs were submitted to a more thorough inspection.

The slaughterhouse of Quito was visited four times during February and March 2001. A total of 472 blood samples were collected and 432 carcasses inspected. In this slaughterhouse the workload is heavier, yet inspection of the predilection sites is 
supposed to be part of the routine. Here again, positive cases were subjected to a thorough inspection.

\subsection{Pigs}

During 1998, on a total of 8154 carcasses, no infected carcasses were officially reported in the metropolitan slaughterhouse of Quito. This is the main slaughterhouse in the Sierra, where pigs from various regions are presented. For this apparent lack of detection, it was decided to concentrate activities on Imbabura province.

Two surveys were held in a slaughterhouse in Ibarra, where only local pigs are slaughtered. During the first survey, between February and April 1998, 1101 porcine carcasses were inspected by means of a single incision in the Musculus masseter, Musculus biceps brachii, Musculus trapezius cervicis, Musculus glutaeus superficialis, and by superficial inspection of the tongue, heart and diaphragm muscles. In addition, blood samples were randomly taken from 591 of these pigs. In the second survey from February until April 1999, 1795 pigs were sampled. Every carcass that was found positive for cysticercosis by routine meat inspection was subjected to a more profound examination, as agreed by the local authorities, which consisted of inspection of the brains and a total larval count of the tongue, heart and diaphragm. It was calculated that the remaining muscle mass represented on average $47 \%$ of the carcass weight. The larval burden of that mass was estimated by a larval count in $100 \mathrm{~g}$ of each of the following muscle groups: M. masseter, M. biceps brachii, Musculus longissimus dorsi, Musculus psoas minor and M. glutaeus superficialis. Thus, on the basis of the larval counts in the muscle samples (lg), the carcass weight $(w)$ plus the sum of the larvae in the brains (lb), tongue, heart and diaphragm (lc), the total larval load could be estimated as $\lg \times 2 \times(w / 100 \times 47)+1 b+1 c$. Organs, viscera and the inner surface of the carcass were macroscopically inspected for other plathelminthes.

\subsection{Humans}

\subsubsection{Human cysticercosis}

Between October 1997 and May 2002, 2368 blood samples were collected from inhabitants of Pichincha, visiting a health centre and 1938 blood samples from inhabitants of Imbabura province, consisting of 1292 samples from volunteers and 646 samples from patients, sent by general practitioners because of neurological complaints. The last group of patients volunteered, after informed consent, to have their sera analysed by the Ag-ELISA as described below and, when positive, to undergo a CT-scan of the brains. These scans were made by a CTMAX 640 "General Electric" and analysed by experienced neurologists. Samples came from both genders and age varied from 12 to 80 years.

\subsubsection{Taeniosis}

From January 2000 until May 2002, a total of 1935 faecal samples from human volunteers were collected: 695 samples came from inhabitants of Pichincha Province and 1240 from various rural communities of Imbabura province. Taenia carriers were offered anthelmintic treatment i.e. a single oral dose of praziquantel at $10 \mathrm{mg} / \mathrm{kg}$ b.w. and stools for species 
identification of the collected tapeworms. In this study, both genders between 1 and 80 years were included.

\subsection{Techniques}

\subsubsection{Stool examination}

Stool samples were examined by the Ritchie technique.

\subsubsection{Identification of cestodes}

Metacestodes encountered in the muscles were dissected out and transferred to $90 \mathrm{ml}$ saline plus $10 \mathrm{ml}$ bovine bile at $37^{\circ} \mathrm{C}$ to allow evagination and visualisation of the scolex.

Tapeworms collected from human stools following praziquantel treatment were identified according to the methods described by Rodriguez-Hidalgo et al. (2002).

\subsubsection{Detection of circulating antigens (Ag-ELISA)}

Blood samples were kept at $4{ }^{\circ} \mathrm{C}$, centrifuged at $2500 \times g$ for 5 min and serum stored at $-20{ }^{\circ} \mathrm{C}$ until use. Sera from bovines, pigs and humans was tested in an Ag-ELISA (Brandt et al., 1992) with the modifications, including pre-treatment of the sera by trichloroacetic acid, as described by Dorny et al. (2000) and Erhart et al. (2002). To facilitate comparison between different plates, all results were expressed as a ratio, calculated by dividing the optical density of each sample by the cut-off value. This cut-off was calculated using a $t$-test based on the optical densities of eight negative samples of Ecuadorian origin, as such, any value above 1 is considered as being positive.

\section{Results}

An overview of the diagnosis of cysticercosis in the respective hosts, the results of carcass inspections in bovines and pigs and the coprological survey are presented in Table 1.

\subsection{Bovine cysticercosis}

Inspection on 374 carcasses in the slaughterhouse of Ibarra revealed one positive animal $(0.27 \%)$. From the 397 sera collected, 23 were seropositive $(5.79 \%$; ratio range: 1.01-128.32) in the Ag-ELISA. This parasitologically positive animal had an Ag-ELISA ratio of 128.32. It was a 1 -year-old steer of $350 \mathrm{~kg}$ from Carchi, in the northern part of the country. It was heavily infected with over 4000 metacestodes, mainly viable.

Meat inspection yielded two positives out of the 432 carcasses $(0.46 \%)$ inspected in the Metropolitan slaughterhouse of Quito; out of the 472 bovine sera, 12 (2.54\%) were positive in Ag-ELISA. In spite of a thorough search of the viscera and the carcass in both animals, only one living metacestode was found, each time located in the oesophagus muscle. One of the positive animals was seronegative in the Ag-ELISA whereas the other had a ratio of 1.4. Both animals were Zebu cross-breds, originating from Pichincha province with a liveweight of about $200 \mathrm{~kg}$. 
Table 1

Diagnosis of cysticercosis in bovines and pigs according to official inspection in the slaughterhouses in Quito (Pichincha Province) and Ibarra (Imbabura Province) and by the detection of circulating antigen in sera from bovines, pigs and humans. Detection of Taenia spp. by microscopical examination of faeces ${ }^{\mathrm{a}}$

\begin{tabular}{|c|c|c|c|c|c|c|}
\hline \multirow[t]{2}{*}{ Province } & \multicolumn{2}{|c|}{ Bovine cysticercosis } & \multicolumn{2}{|l|}{ Porcine cysticercosis } & \multirow{2}{*}{$\begin{array}{l}\text { Human cysticercosis } \\
\text { Ag-ELISA }\end{array}$} & \multirow{2}{*}{$\begin{array}{l}\text { Taeniosis } \\
\text { Ritchie }\end{array}$} \\
\hline & Ag-ELISA & Post mortem & Ag-ELISA & Post mortem & & \\
\hline Pichincha & $2.54(12 / 472)$ & $0.46(2 / 432)$ & - & $(0 / 8154)$ & $4.90(116 / 2368)$ & $2.45(17 / 695)$ \\
\hline Imbabura & $5.79(23 / 397)$ & $0.27(1 / 374)$ & $6.77(40 / 591), 12.02(53 / 441)$ & $0.73(8 / 1101), 0.39(7 / 1795)$ & $5.11(99 / 1938)$ & $1.05(13 / 1240)$ \\
\hline Total & $4.03(35 / 869)$ & $0.37(3 / 806)$ & $9.01(93 / 1032)$ & $0.52(15 / 2896)^{b}$ & $4.99(215 / 4306)$ & $1.55(30 / 1935)$ \\
\hline
\end{tabular}

${ }^{\text {a }}$ Percentage positives (number of positive cases/number examined).

${ }^{\mathrm{b}}$ Excluding data from Pichincha. 
Dissection of the larvae and evagination revealed morphological features i.e. an unarmed scolex, typical for $T$. saginata metacestodes.

\subsection{Porcine cysticercosis}

During the first survey in the slaughterhouse of Ibarra, post mortem inspection of 1101 carcasses revealed eight positives $(0.73 \%)$. Forty out of 591 blood samples $(6.77 \%)$ were positive in the Ag-ELISA. In the second survey in the same slaughterhouse 7 of the 1795 carcasses $(0.39 \%)$ were found positive by the meat inspector. Results of the more thorough dissections of these seven pigs and their estimated total larval burden are given in Table 2 . In the Ag-ELISA, 53 pigs out of the 441 (12.02\%) were positive, among which pigs 1 and 2 that were thoroughly dissected (Table 2). No blood samples were collected from the five other parasitologically positive pigs. Fasciola spp. was found in two pigs, both seronegative for cysticercosis, hydatid cysts were found in four pigs seronegative for cysticercosis and in one seropositive pig with a ratio of 9. Cysticercus tenuicollis was found in six pigs, all with a ratio between 3 and 11. Discounting seven possible cross-reactions, $10.66 \%$ of the pigs were seropositive.

\subsection{Human cysticercosis}

Cysticercus cellulosae circulating antigen was detected in 215 serum samples in a total of 4306 serum samples (4.99\%), with little variation between provinces: 116 positives out of 2368 in Pichincha (4.90\%) and 99 positives out of 1938 samples tested from Imbabura province $(5.11 \%)$. However, in the latter group $3.4 \%$ of the volunteers were positive whereas analysis by Ag-ELISA of the 646 neurological patients revealed 55 seropositives $(8.51 \%)$. Brain CT-scans of these 55 patients resulted in 52 diagnoses of neurocysticercosis, the majority, however, i.e. 36 out of 52, without any complaints suggestive for cysticercosis, only three had a history of epileptic crises and 13 patients complained of recurrent headache problems.

Table 2

Porcine cysticercosis in Imbabura province ${ }^{\mathrm{a}}$

\begin{tabular}{llrrrrrr}
\hline Pig no. & \multicolumn{2}{l}{ Number of larvae in } & & \multicolumn{2}{l}{$\begin{array}{l}\text { Carcass } \\
\text { weight (kg) }\end{array}$} & $\begin{array}{l}\text { Estimated } \\
\text { (total no. of cysticerci) }\end{array}$ \\
\cline { 2 - 6 } & Brains & Tongue & Heart & Diaphragm & $\begin{array}{l}\text { Muscle } \\
\text { groups }\end{array}$ & \\
\hline 1 & 1 & 1 & 2 & 3 & 10 & 30 & 289 \\
2 & 3 & 4 & 17 & 6 & 12 & 60 & 707 \\
3 & 1 & 78 & 0 & 21 & 225 & 30 & 6445 \\
4 & 5 & 6 & 0 & 10 & 59 & 50 & 2794 \\
5 & 2 & 23 & 17 & 0 & 269 & 25 & 6364 \\
6 & 1 & 0 & 5 & 4 & 23 & 25 & 551 \\
7 & 2 & 1 & 5 & 17 & 60 & 60 & 3409 \\
\hline
\end{tabular}

\footnotetext{
${ }^{a}$ Results of thorough dissection of seven pigs found positive at routine meat inspection and estimation of the total number of metacestodes.
} 


\subsection{Human taeniosis}

Coprological examination of 1935 stool samples resulted in 30 positive cases $(1.55 \%)$ with 17 out of $695(2.45 \%)$ from Pichincha and 13 out of $1240(1.05 \%)$ from Imbabura province. The vast majority of stool samples $(93 \%)$ were positive for either helminths $(14 \%)$ or protozoan parasites $(35 \%)$ or both $(43 \%)$.

Praziquantel treatment resulted in recuperation of adult tapeworms from 17 hosts in Pichincha, 16 of these were identified as T. saginata, one as T. solium. In Imbabura, five hosts carried $T$. saginata, seven $T$. solium and in one case no worms could be recuperated. All hosts carried a single worm, except for one carrying a very small and two normal sized T. saginata.

\section{Discussion and conclusion}

Some authors (Heinz and MacNab (1965) cited by Joubert and Evans (1997)) found it striking that high rates of cases of human cysticercosis occur while the prevalence of intestinal $T$. solium in man is notoriously low and nicknamed this disproportion the " $T$. solium/cysticercosis paradox". In Ecuador, according to the scarce epidemiological data provided by the Ecuadorian Ministry of Public Health (Aguilar, 2002), in some provinces in the Sierra, like Bolivar, Cañar and Imbabura this paradoxical situation seems to exist as well, with official incidences of taeniosis/cysticercosis of $0 / 1.60,0 / 1.36$ and $0 / 3.57$, per 100,000 habitants, respectively. Whereas, in the coastal provinces of Esmeraldas, Los Rios and Manabi the reverse has been reported i.e. the presence of adult Taenia with no or hardly any cases of human cysticercosis, i.e. 1.36/0, 11.11/0.30 and 1.01/0 per 100,000 habitants, respectively.

From 1985 to 2001, according to FAO, WHO and OIE reports, no data on Cysticercus bovis in Ecuador, are available in spite of being notifiable (Welte, 1997; Handistatus II, 2002), before 1985, it was listed as exceptional. Even, a report specifying adult $T$. saginata has never been made in Ecuador where usually prevalences of Taenia are given without reference to the species (e.g. López, 1969). All references to adult Taenia were assumed to be $T$. solium, presumably because of the impact on public health.

This study confirms the presence of bovine cysticercosis in Ecuador, commonly assumed to be absent. This is very surprising and the latter statement may be untrue for the staff of slaughterhouses, which either did not report their observations or failed to recognise the metacestodes, hence officially $C$. bovis was considered to be either absent or at least present but beyond the detectable limit. The comparison with the study of Dorny et al. (2000) in Belgian cattle is interesting: $0.26 \%$ positives on post mortem inspection vs. $3.09 \%$ seropositives in Belgium with $0.37 \%$ positives on carcass inspection vs. $4.03 \%$ seropositives in the present study or an almost equal ratio (12 against 11 , respectively) by which the post mortem data have to be multiplied to obtain the seroprevalences.

Even with proper training and supervised inspection, as in the present study, regional variations on cysticercosis in Ecuador will remain as indicated by official data (Aguilar, 2002) on human and porcine cysticercosis. 
Estimating the prevalence of porcine cysticercosis is even more difficult. Ante mortem palpation of the tongue is a common practice on the markets in the region. As long as no financial compensation for condemnation of cysticercotic carcasses, through insurance or subvention, exists, it will be unlikely that animals with palpable cysticerci in the tongue will be presented in official slaughterhouses. On the other hand, all positive carcasses had high numbers of cysticerci which may suggest that light infections might escape the attention of the inspector. This may be a partial explanation of the failure to detect no positive carcasses on a total of 8154 pigs slaughtered in Pichincha, even more so since official meat inspection, limited to superficial inspection and a single incision only, was carried out without any intervention of the present investigators.

In any case, the limited number of complete dissections of the carcass does not allow any firm conclusion but data are not suggestive for clear-cut predilection sites of the metacestodes. The brains, however, of all seven pigs harboured cysticerci albeit in very low numbers, irrespective of the total larval load. Incidentally, routine post mortem inspection never includes the brains. The presence of porcine cysticercosis, in the Northern Andes of Ecuador as determined by Ag-ELISA lies well in the expected range of an endemic region i.e. 5-30\% (Craig et al., 1996). The monoclonal antibodies, used in the latter test, were raised against metabolic antigens of $T$. saginata metacestodes (Brandt et al., 1992), as such, if those are reacting with antigens of $T$. solium metacestodes, then a cross-reaction with Taenia hydatigena metacestodes is equally likely. Therefore, the six cases of $C$. tenuicollis found in the $53 \mathrm{Ag}$-ELISA positives in Imbabura were discounted.

As for the infection rates of human cysticercosis, we cannot rule out a biased sampling. Samples came from patients visiting the outpatient's hospital and their willingness or that of the volunteers to co-operate might have been linked to being suspicious of a problem. Again in this study, the occurrence of intestinal Taenia seems low and probably an underestimation, even when these data, obtained by microscopy have to be multiplied by 2.6 (Allan et al., 1996). Nevertheless the official figures for 2001 (Aguilar, 2002) do not seem to be very realistic i.e. 1 and 2.15 cases of taeniosis and cysticercosis, respectively, per 100,000 habitants in Pichincha, in Imbabura 3.57 cases of cysticercosis and none for Taenia spp. Rodriguez-Hidalgo et al. (2002) differentiated 16 adult specimen from the same region as $T$. saginata and seven as $T$. solium. In $T$. solium endemic regions, prevalence of taeniosis is usually not higher than $1 \%$ (Gemmell et al., 1983) but can reach $2.7 \%$ (Allan et al., 1996). As for T. saginata, Geerts (1990) estimated that the incidence of intestinal $T$. saginata in Belgium was equal or even higher than the cases of bovine cysticercosis detected p.a. Obviously, many factors like culinary traditions or food-safety regulations, make comparisons about the proportion of adult tapeworm carriers and metacestode infections between different countries are often difficult. In addition, the limited number of samples and the diagnostic insensitivity related to intestinal Taenia does not allow a conclusion on the proportion in which both intestinal Taenia spp. are present. However, in Ecuador, our study confirms the presence of both Taenia spp. Given the relatively high numbers of bovine, porcine and human cysticercosis it is unlikely that current official estimates about the presence of adult Taenia are realistic which hinders a correct understanding of the epidemiology of the $T$. solium/cysticercosis complex. 


\section{Acknowledgements}

This study was carried out with the financial support of VLIR (Vlaamse Interuniversitaire Raad-Flemish Interuniversity Coucil), and the Universidad Central del Ecuador. Part of the research was done within the framework agreement between the Belgian Directorate General for International Co-operation and the Institute of Tropical Medicine, Antwerp. The authors are indebted to the medical staff of the hospital in Atuntaqui, to the staff of the "Camal Metropolitano" in Quito, the "Camal Municipal de Rastro" in Ibarra and to the patients for their willingness to participate in this study.

\section{References}

Aguilar, E.J., 2002. Estadisticas de las enfermedades de notificación obligatoria. EPI-2. Número de casos e incidencia acumulada anual de cisticercosis en el Ecuador, vol. 10. Ministerio de Salud Pública del Ecuador. Dirección Nacional de Epidemiología, Quito, Ecuador, pp. 1-42.

Allan, J.C., Velasqueztohom, M., Garcianoval, J., Torresalvarez, R., Yurrita, P., Fletes, C., Demata, F., Dealfaro, H.S., Craig, P.S., 1996. Epidemiology of intestinal taeniasis in four, rural, Guatemalan communities. Ann. Trop. Med. Parasitol. 90, 157-165.

Aragundi, M., 1969. Incidencia de Cysticercus bovis en los bovinos que se despostan en el matadero y frigorífico Guayaquil S.A. Tesis de Doctor en Medicina Veterinaria. Facultad de Agronomía y Veterinaria, Universidad de Guayaquil.

Aragundi, F., 1999. Determinar cisticercosis bovina en el matadero municipal de la ciudad de Guayaquil. Tesis de Doctor en Medicina Veterinaria y Zootecnía. Facultad de Medicina Veterinaria y Zootecnía, Universidad Estatal de Guayaquil.

Benítez, W., 1995. El sistema tradicional de producción porcina. FAO, 160 pp.

Brandt, J.R.A., Geerts, S., De Deken, R., Kumar, V., Ceulemans, F., Brijs, L., Falla, N., 1992. A monoclonal antibody-based ELISA for the detection of circulating excretory-secretory antigens in Taenia saginata cysticercosis. Int. J. Parasitol. 22, 471-477.

Briones, G.M., 1969. Investigación de Cysticercus bovis, en el ganado vacuno sacrificado en el matadero de la ciudad de Portoviejo. Tesis de Doctor en Medicina Veterinaria y Zootecnia. Facultad de Medicina Veterinaria y Zootecnia, Universidad Técnica de Manabí.

Craig, P.S., Rogan, M.T., Allan, J.C., 1996. Detection, screening and community epidemiology of taeniid cestode zoonoses: cystic echinococcosis, alveolar echinococcosis and neurocysticercosis. Adv. Parasitol. 38, 169-250.

Cruz, I., 1996. Epidemiología de la Neurocisticercosis en Ecuador. En: Teniasis/Cisticercosis por Taenia solium. In: García, H., Martínez, M. (Eds.), Editorial Universo S.A., vol. 2. Lima-Perú, pp. 303-312.

Cruz, M., Davis, A., Dixon, H., Pawlowski, Z., Proaño, J., 1989. Operational studies on the control of Taenia solium taeniasis/Cysticercosis in EcuadorBull World Health Organisation, vol. 64, No. 4, pp. 401-407.

Dorny, P., Vercammen, F., Brandt, J., Vansteenkiste, W., Berkvens, D., Geerts, S., 2000. Sero-epidemiological study of Taenia saginata cysticercosis in Belgian cattle. Vet. Parasitol. 88, 43-49.

Erhart, A., Dorny, P., Van De, N., Vien, H.V., Thach, D.C., Toan, N.D., Cong, L., Geerts, S., Speybroeck, N., Berkvens, D., Brandt, J., 2002. Taenia solium cysticercosis in a village in northern Viet Nam: seroprevalence study using an ELISA for detecting circulating antigen. Trans. Roy. Soc. Trop. Med. Hyg. 96, 270-272.

Geerts, S., 1990. Taenia saginata: een eeuwig probleem? Verhandelingen van de Koninklijke Academie voor Geneeskunde van België LII, pp. 537-564.

Gemmell, M., Matyas, Z., Pawlowski, Z., Soulsby, E.J.L. (Eds.), 1983. Guidelines for the Surveillance, Prevention and Control of Taeniasis/cysticercosis. World Health Organization, Geneva.

Handistatus II, 2002. http://www.oie.int/hs2/report.asp (updated 11 December 2002; cited 12 December 2002).

Intriago, J., 1976. Análisis de investigaciones de las lesiones anatomopatológicas microscópicas. Causa de decomiso en bovinos en los mataderos de MIFGSA municipal de Eloy Alfaro. Tesis de Doctor en Medicina Veterinaria. Facultad de Agronomía y Veterinaria, Universidad de Guayaquil. 
Jiménez, B., 1976. La cisticercosis por C. cellulosae y como zoonosis. Boletín de la Oficina Sanitaria Panamericana 80 (5), 403-410.

Joubert, J.J., Evans, A.C., 1997. Current status of food-borne parasitic zoonoses in South Africa and Namibia. SE Asian J. Trop. Med. Public Health 28 (Suppl.), 7-10.

López, R., 1969. Incidence of intestinal parasites in Bahia de Caraquez and surrounding areas of the Province of Manabí. Rev. Ecuator. Hig. Med. Trop. 26, 137-140.

Pawlowski, Z., Schultz, M.G., 1972. Taeniasis and cysticercosis (Taenia saginata). Adv. Parasitol. 10, $269-343$.

Rodriguez-Hidalgo, R., Geysen, D., Benítez-Ortiz, W., Geerts, S., Brandt, J., 2002. Comparison of conventional techniques to differentiate between Taenia solium and Taenia saginata and an improved polymerase chain reaction-restriction fragment length polymorphism assay using a mitochondrial $12 \mathrm{~S}$ rDNA fragment. J. Parasitol. 88, 1007-1011.

Sosa, A., 1981. Investigación de Cysticercus inermis en bovinos despostados en el matadero municipal de la ciudad de Esmeraldas. Tesis de Doctor en Medicina Veterinaria. Facultad de Agronomía y Veterinaria. Universidad de Guayaquil.

Welte, V.R., 1997. Animal Yearbook 1995. Food and Agricultural Organization, Rome, Italy, 279 pp. 